\title{
A feasibility study for implementing advanced control of a heating system
}

\author{
Valerii Fomin ${ }^{1, *}$ \\ ${ }^{1}$ Saint Petersburg State University of Architecture and Construction. Saint Petersburg, Russian Federation
}

\begin{abstract}
The article justifies the necessity of implementation of a new technique of controlling heat consumption by a heating system. The formation of a heat carrier's parameters from the beginning of heat generation until supply to the consumer's premises has been discussed. An analysis of heat energy overconsumption in the period of increased external air temperature during automatic regulation in accordance with external air temperature is presented. The parameters not accounted for in the generation of a controlling signal under the current practices of regulating the heating of buildings.
\end{abstract}

\section{Introduction}

The enhanced requirements to reductions of specific heat losses for heating [1] are conducive to searching for ways $[2,3,4,5,6,7]$ to optimize heat consumption for heating systems of apartment residential and public buildings. The application of heat consumption system controllers in heat network connection assembles has opened new opportunities in improvement of regulation algorithms and individual approach to the generation of heat consumption conditions of each building. At the same time, the diversity of manufacturers of control automatics has created tools to increase efficiency of using heat energy when controlling heating systems. At the same time, the diversity of manufacturers of control automatics implies deep studies of the software functions of the equipment therewith complicating their efficient use by servicing personnel. The non-use of the automatic potential fully often does not justify the expectations of interested parties (consumers of heat energy) and delays further implementation of energy-saving technologies.

\section{Formation of the heat carrier's temperature}

Currently the mechanism of formation of the temperature on the premises of a building with central heat supply is as follows (Fig. 1). At the outlet of a power facility (heat power station, district boiler house) the parameters of a supplying heat carrier are formed: temperate 2.1 and pressure 2.2 (Fig. 1) in accordance with the applicable law [8] on the basis of average temperatures 1 (Fig. 1). The proposed methodologies of the outgoing parameters including [9] are above all conducive to the enhancement of operation characteristics of the heat installation itself, but not of the end consumers of the heat energy. As the heat carrier is transported, its parameters are reduced due to the influence on it of both its design features 3.1 (Fig. 1) [10] and weather conditions 3.2 (Fig. 1) [11]. Thus, at the boundary of the heat network and the heating unit the parameters can considerably differ de-pending on the distance from the power facility to the building. The heating unit equipped with control automatics must account for changes in the parameters occurring at the boundary of the connection to the heat network, and generate the characteristics of the heat carrier: temperature 5.1 and pressure 5.2 (Fig.1) to the consumer's premises, the consumption of the heat carrier taking account of the current exterior air temperature 4 (Fig. 1). Having various versions of controllers offered by manufacturers [12, 13] available, the most widespread practical way of the heat carrier's temperature formation is according to the supplying heat carrier's temperature. When an external air temperature changes, a signal enters a controller that verifies, in accordance with the control temperature schedule, the correspondence of the temperature of the supplying heatcarrier of the heating system and sends a command to the electric drive of the control valve that makes an opening or a closing, striving to bring the sensors' readings to correspond to the schedule. At that, the controller does not generate a base of parameters of individual characteristics of heat consumption of the facility to pick up an individual temperature schedule, but depends on the right adjustment of the temperature schedule, i.e. the competence and responsibility of the adjustment personnel.

\footnotetext{
* Corresponding author: sienef@yandex.ru
} 


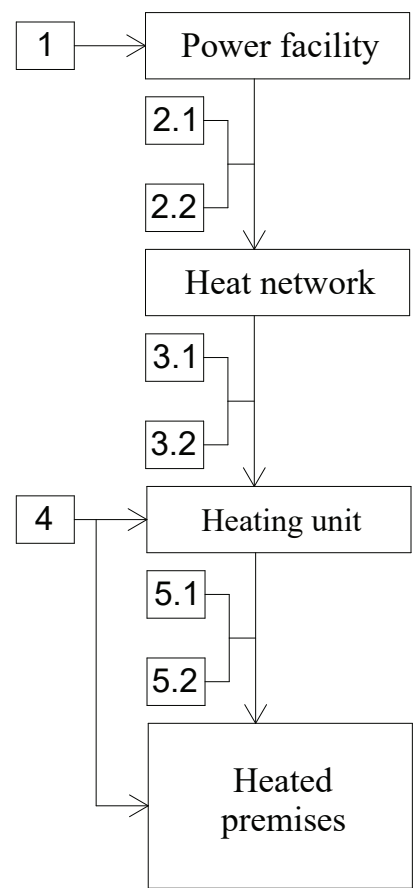

Fig. 1. Formation of the heat carrier's temperature.

Thus, the current features of the equipment of the control systems are unable to ensure comfortable temperatures $[14,15]$ on the premises of a building due to incomplete accounting for of disturbing factors when determining the quantity of heat for heating

\section{A practical example of overconsumption of heat energy in automatic heating control}

The obviousness of implementing adaptive control systems and inclusion in the process of generating quantities of heat required for creating comfortable temperatures is confirmed by an analysis of the heat consumption of the building equipped with temperature control automatics. These heat consumptions indicate heat energy overconsumptions in the period of exterior air temperature rise. be centred and should be numbered with the number on the right-hand side.

To determine the heating characteristic of a building, we will use the formula (1):

$$
q_{v} \cdot V_{\mathrm{bld}}=\frac{Q}{t_{\mathrm{int}}-t_{\text {ext }}}
$$

where: $\mathrm{q}_{\mathrm{v}}$ is specific heating characteristic of a building,

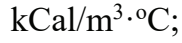

$\mathrm{V}_{\text {bld }}$ is volume of the building, $\mathrm{m}^{3}$;

$\mathrm{Q}$ is heat losses of the building, $\mathrm{GCal} / \mathrm{h}$;

$\mathrm{t}_{\text {int }}$ is internal air temperature, ${ }^{\circ} \mathrm{C}$;

$\mathrm{t}_{\text {ext }}$ is external air temperature, ${ }^{\circ} \mathrm{C}$;

To enhance visibility of the dynamics of changes in the heat consumption on the graphs, the volume of the building is withdrawn from the formula.
As one of the examples let us consider a new brick monolithic building of the volume $63,854 \mathrm{~m}^{3}$ located in Saint Petersburg and commissioned in 2009 . The heating power plant is equipped with an automated individual heating unit with ECL 300 controller (Danfloss). The connection of the heating system is independent with an option of control by risings mains (balancing valves) and thermostatic heads on heatsinks.

Table 1 shows the actual (a heat calculator of the heat energy meter, HEM) and calculated data showing the construction and thermotechnical characteristics of the building.

Table 1. Heating system parameters.

\begin{tabular}{|c|c|c|c|c|c|c|c|c|}
\hline \multirow[t]{2}{*}{ Date } & \multicolumn{5}{|c|}{ Actual data of HEM } & \multicolumn{3}{|c|}{ Calculated data } \\
\hline & $\begin{array}{l}\mathbf{T}_{\text {ext, }}, \\
{ }^{\circ} \mathrm{C}\end{array}$ & $\begin{array}{l}\mathbf{G}, \\
\text { t/day }\end{array}$ & $\begin{array}{l}\mathrm{T}_{1}, \\
{ }^{\circ} \mathrm{C}\end{array}$ & $\begin{array}{l}\mathrm{T}_{2}, \\
{ }^{\circ} \mathrm{C}\end{array}$ & $\begin{array}{c}\text { Qact, } \\
\text { GCal/ } \\
\text { day }\end{array}$ & \begin{tabular}{|c}
$\mathbf{Q}_{\text {calc, }}$ \\
GCal$/$ \\
day \\
\end{tabular} & \begin{tabular}{|c|}
$\mathbf{q}_{\mathbf{v}} \cdot \mathbf{V}_{\text {bld }}$, \\
$\mathrm{kCal} \cdot$ \\
$\mathrm{day} /{ }^{\circ} \mathrm{C}$
\end{tabular} & $\begin{array}{l}\eta \\
\% \\
\%\end{array}$ \\
\hline 01.01 .17 & 1,2 & 142,60 & 72,8 & 47,6 & 5,40 & 5,36 & 11,35 & 1 \\
\hline 02.01 .17 & $-2,1$ & 174,26 & 76,0 & 49,9 & 6,60 & 6,30 & 11,89 & 5 \\
\hline 03.01 .17 & $-7,8$ & 183,43 & 79,9 & 51,9 & 7,60 & 7,92 & 10,99 & -4 \\
\hline 04.01 .17 & $-14,5$ & 166,26 & 86,6 & 53,6 & 8,60 & 9,80 & 10,10 & $\overline{14}$ \\
\hline 05.01 .17 & $-18,1$ & 156,98 & 92,1 & 54,9 & 9,57 & 10,83 & 10,20 & $\overline{13}$ \\
\hline 06.01 .17 & $-18,6$ & 148,10 & 92,7 & 54,6 & 9,68 & 10,97 & 10,20 & $\begin{array}{c}- \\
13\end{array}$ \\
\hline 07.01 .17 & $-18,4$ & 146,27 & 92,8 & 54,1 & 9,72 & 10,92 & 10,28 & $\overline{12}$ \\
\hline 08.01 .17 & $-9,4$ & 143,08 & 93,3 & 54,7 & 9,81 & 8,35 & 13,47 & 15 \\
\hline 09.01 .17 & $-1,1$ & 73,48 & 93,1 & 51,5 & 7,63 & 5,99 & 14,41 & 21 \\
\hline 10.01 .17 & 0,8 & 38,90 & 93,5 & 50,8 & 6,50 & 5,47 & 13,40 & 16 \\
\hline 11.01 .17 & $-4,3$ & 82,40 & 91,5 & 51,8 & 7,62 & 6,92 & 12,54 & 9 \\
\hline 12.01 .17 & $-3,7$ & 87,75 & 91,8 & 51,9 & 7,75 & 6,75 & 13,07 & 13 \\
\hline 13.01 .17 & $-2,2$ & 73,45 & 91,2 & 52,2 & 7,25 & 6,32 & 13,01 & 13 \\
\hline 14.01 .17 & 0,0 & 57,87 & 89,4 & 50,6 & 6,40 & 5,70 & 12,68 & 11 \\
\hline 15.01 .17 & $-0,9$ & 64,84 & 87,5 & 50,9 & 6,48 & 5,95 & 12,33 & 8 \\
\hline 16.01 .17 & $-2,8$ & 77,37 & 87,2 & 51,3 & 6,73 & 6,50 & 11,76 & 3 \\
\hline 17.01 .17 & $-4,0$ & 99,13 & 86,8 & 51,6 & 7,12 & 6,81 & 11,89 & 4 \\
\hline 18.01 .17 & $-1,9$ & 91,50 & 87,5 & 50,9 & 6,91 & 6,22 & 12,60 & 10 \\
\hline 19.01 .17 & 0,9 & 53,61 & 88,2 & 50,5 & 6,05 & 5,42 & 12,56 & 10 \\
\hline 20.01 .17 & $-0,5$ & 68,31 & 87,3 & 50,8 & 6,37 & 5,83 & 12,34 & 8 \\
\hline 21.01 .17 & $-3,5$ & 96,29 & 86,9 & 51,6 & 7,08 & 6,69 & 12,03 & 6 \\
\hline 22.01 .17 & $-1,4$ & 79,30 & 87,5 & 51,5 & 6,65 & 6,08 & 12,39 & 9 \\
\hline
\end{tabular}

where: $\mathrm{T}_{\text {ext }}$ is average daily external air temperature, ${ }^{\circ} \mathrm{C}$;

$\mathrm{G}$ is daily consumption of the heat carrier for heating, $\mathrm{t}$ /day; 
$\mathrm{T}_{1}$ is average daily temperature of the heat carrier in the supplying pipeline, ${ }^{\circ} \mathrm{C}$;

$\mathrm{T}_{2}$ is average daily temperature of the heat carrier in the return pipeline, ${ }^{\circ} \mathrm{C}$;

$\mathrm{Q}_{\text {act }}$ is actual daily heat consumption, ${ }^{\circ} \mathrm{C}$;

$\mathrm{Q}_{\text {calc }}$ is calculated daily heat consumption, ${ }^{\circ} \mathrm{C}$;

$\mathrm{q}_{\mathrm{v}} \cdot \mathrm{V}_{\text {bld }}$ is specific heating characteristic of a building for the total volume of the building, $\mathrm{kCal} \cdot \mathrm{day} /{ }^{\circ} \mathrm{C}$;

$\eta$ is deviation of actual heat consumption from calculated heat consumption $\left(\mathrm{Q}_{\text {act }}-\mathrm{Q}_{\text {calc }}\right) / \mathrm{Q}_{\text {act }} \cdot 100$, characterizing the overheating and underheating of the building, $\%$

On graph 1 one can see the region of overheating, the region $\mathrm{Q}_{\text {calc }}$ located above $\mathrm{Q}_{\text {act }}$ and characterizing the "excess" of heat upon an increase in external air temperature.

Graph 1. Heating system parameters.

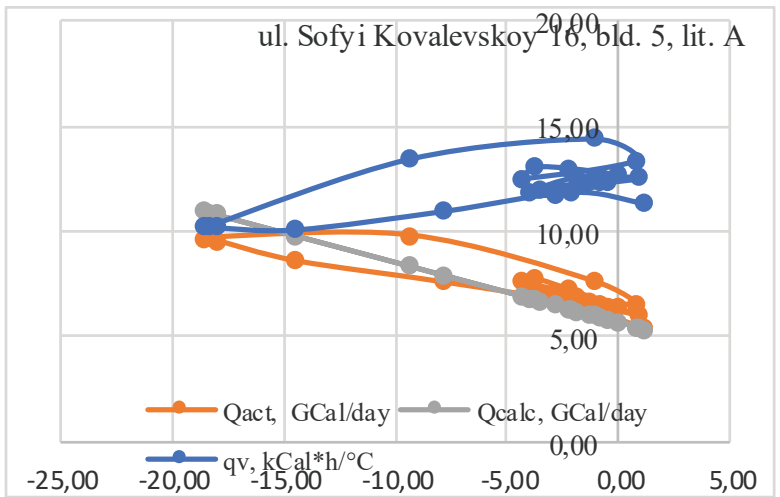

This residential building has the potential to reduce heat consumption due to the fact that the specific heating load of the building grows with an increase in the external air temperature, and the temperature in the apartments did not drop was in the range of $21 \div 28{ }^{\circ} \mathrm{C}$.

On the basis of the table of the average external air temperature $\mathrm{t}\left({ }^{\circ} \mathrm{C}\right)$ and the heat consumption Q (GCal) on the heating system per month the graphs have been built.

Table 2. Average temperature and heat consumption.

\begin{tabular}{|c|c|c|c|c|c|c|c|}
\hline $\begin{array}{c}\text { Heating } \\
\text { season }\end{array}$ & $\begin{array}{c}\text { Octob } \\
\text { er }\end{array}$ & $\begin{array}{c}\text { Novem } \\
\text { ber }\end{array}$ & $\begin{array}{c}\text { Decem } \\
\text { ber }\end{array}$ & $\begin{array}{l}\text { yanuar } \\
\text { yebru }\end{array}$ & March & April \\
\hline \multirow{2}{*}{$2013-$} & 7,3 & 4,4 & 0,9 & -7 & 0 & 2,2 & 6,5 \\
\cline { 2 - 8 } 2014 & 117,71 & 144,07 & 182,59 & 229,40 & 255,25 & 146,29 & 135,14 \\
\hline \multirow{2}{*}{$\begin{array}{c}2014- \\
2015\end{array}$} & 5,2 & 0,8 & -1 & $-2,7$ & $-0,6$ & 2,6 & 5,1 \\
\cline { 2 - 8 } & 97,58 & 177,42 & 197,10 & 237,49 & 207,34 & 135,14 & 114,86 \\
\hline \multirow{2}{*}{$2015-$} & 5,6 & 3,1 & 2,1 & $-11,2$ & 0 & 1 & 6,3 \\
\cline { 2 - 8 } 2016 & 69,67 & 127,46 & 134,73 & 249,88 & 177,00 & 165,34 & 134,56 \\
\hline \multirow{2}{*}{$2016-$} & 5 & $-1,8$ & $-1,2$ & $-3,9$ & $-3,5$ & 1,3 & 2,8 \\
\cline { 2 - 8 } 2017 & 110,92 & 187,12 & 206,37 & 212,40 & 199,86 & 157,35 & 126,12 \\
\hline
\end{tabular}

Graph 2. Average temperature.

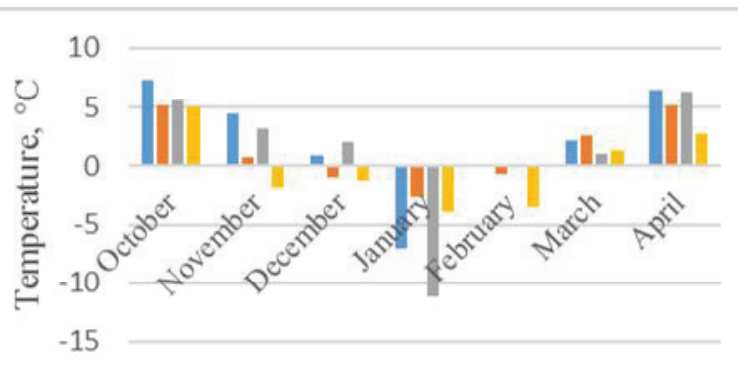

[ 2013-2014 =2014-2015 ㅁ 2015-2016 = 2016-2017

Graph 3. Heat consumption.

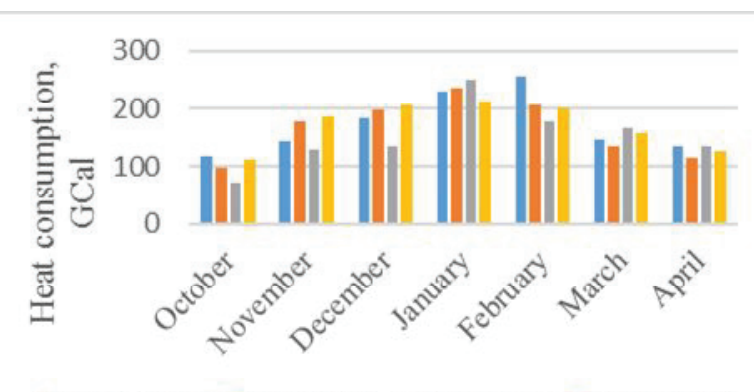

| 2013-2015 | 2014-2016 | 2015-2017 |

A conclusion can be drawn from the given schedules that there is no direct dependency of the building's heat consumption on external air temperature, which shows the insufficiency of this criterion in the efficient control of the heating system. Thus, the absolute conventionality is confirmed, taken when making an analysis of an energy-saving event on the criterion of external air temperature due to the imperfection as the only disturbing parameter.

\section{Parameters not accounted for}

Thus, to maintain the required comfort on the premises intended for various uses, one has to identify the factors (Fig. 2) not accounted for in the control process, but influencing the quantities of heat energy when the building is heated. The parameters influencing the heat consumption can be conditionally divided into disturbing and static ones.

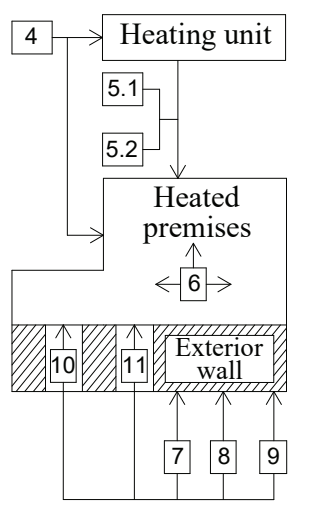

Fig. 2. Parameters not accounted for. 


\subsection{Disturbing parameters}

The disturbing parameters are in their turn divided into interior and exterior ones.

\subsubsection{Interior parameters}

The interior disturbing parameters depend on the intended use of the building and its operating conditions. They include, in the first turn, heat or cold inputs [16] arising in the process of operation of the equipment or activities of people 6 (Fig. 2).

\subsubsection{Exterior parameters}

The wind effects 7 (Fig. 2) on enclosing structures consist of wind velocity and direction with respect to the building facades and are able to considerable increase the heat losses [17]. In the transition period of the heating season the effects of solar radiation increase 8 (Fig. 2) depending on the position of the building in respect of the cardinal directions and the glazing of the facades [18]. The humidity of the enclosing structures 9 (Fig. 2) arising both when precipitation falls and due to the location of the building on the coastal territory of seas and oceans, is able to reduce the thermotechnical characteristics both in current time and having effects when they are operated [19].

\subsection{Statistical parameters}

The statistical parameters are characterized by individual architectural 10 (Fig. 2) and thermotechnical features 11 (Fig. 2) of the building. The degree of influence of the statistical parameters increases with the increase in the effects of the exterior disturbing parameters [20].

\subsubsection{Architecture of the building}

The architectural features of the building, namely the altitude of the building and its compactness are determining ones when the wind or its directions act.

\subsubsection{Thermotechnics of the enclosing structures}

The high thermotechnical characteristics of the enclosing structures of the building with high heat-retaining capacity increase the efficiency of using heat energy with positive fluctuations of the exterior air temperature.

\section{The proposed control method}

The construction of the suggested control model is based on creating an adaptive advanced control system. The purpose of the control consists in searching for an individual approach to the control of each heated building with generation of a base of parameters serving as elements for constant adjustment (adaptation) to changes in disturbing factors taking into account the static characteristics of the building. The determining factor in this system is advanced generation of a controlling signal based on the full range of weather conditions, not on the one, albeit basic, parameter for control, i.e. the exterior air temperature. The issue of advanced control is discussed in the article [21] offering short-term forecast based on daily fluctuations (day/night) of the temperatures. The advantage in implementing this algorithm is attained by using the existing controller installed in a heating unit. The next step in implementing the advanced control of the heating system might be the creation of a system on the basis of local forecast of weather conditions [22], with the use of the practical value of heat accumulation of the building $\beta$ [23] with frequent fluctuations of the exterior air temperature [24].

\section{Conclusion}

The presented practical results of heat consumption of the heating system of a modern residential building evidence the imperfection of local automatic control. The implementation of the advanced control system will make it possible to select an individual control schedule and to increase the efficiency of heat consumption when heating residential and public buildings.

\section{References}

1. Order of the Ministry of Construction of Russia dated 06.06.2016 No.399/order, On approving the Rules for determining the class of power efficiency of apartment buildings

2. Ye.L. Prokopchuk, Patent No.73509 Russian Federation, MPK G05D23/19

3. D.A. Shnaider, V.F. Postaushkin, L.S. Kazarinov, M.V. Shishkin, Patent No.2196274 Russian Federation, MPK F24D19/10

4. M.N. Masov, Patent No.2348061 Russian Federation, MPK G05D23/00

5. I.A. Kashmanov, Patent No.2492392 Russian Federation, MPK F24D3/00

6. A.N. Potapenko, A.V. Belousov, Ye.A. Potapenko, S.V. Kostrikov, Patent No.2247422 Russian Federation, MPK G05D23/19

7. T.A. Datsyuk, Yu.P. Ivlev, V.A. Modern problems of science and education, no.5 (2014)

8. Rules for operation of power stations and networks of the Russian Federation, RD 34.20.501-95

9. R.Yu Rozhkov, Heat supply news, no.2, 24-28 (2013)

10. S.Yu. Andreyev, Bulletin of the National Technical University Kharkov Polytechnic Institute. Series: Informatics and Stimulation, 9-12 (2005)

11. A.N. Ganzha, V.N. Podkopay, Power savings. Power engineering. Power Audit, No.8, 8-13 (2013)

12. Operation manual ECL Comfort 210/310, Danfoss Denmark 
13. Operation manual TPM232M, OVEN Russian Federation

14. GOST 30494-2011, Residential and public buildings. Indoor climate parameters, 2013

15. L. Bankhidi, Heat indoor climate (Stroyizdat, Moscow, 1981)

16. Yu.A. Kuvshinov, Power savings in indoor climate systems of buildings (Publishing house of the Association of construction institutions of higher education, Moscow, 2010)

17. D.V. Drozd, Yu.V. Yelistratova, A.S. Seminenkov, Modern science-intensive technologies, No.8, 37-39 (2013)

18. A.I. Kruglova, Climate and enclosing structures (Stroyizdat, Moscow, 1970)

19. Yu.N. Leontyeva, Forecasting the dynamics of hygrothermal state of enclosing structures of residential buildings of Saint Petersburg and increasing their power efficiency: thesis of cand.of techn.sc. Saint Petersburg (2002) [in Russian]

20. O.D. Samarin, Thermal physics. Power savings. Power efficiency (ASV, Moscow, 2014)

21. Ye.L. Prokopchuk, A synthesis of a system of advanced control of heat supply to heat a building: thesis of cand. of techn.sc. Dzerzhinsk, (2009) [in Russian]

22. A.A. Fevralev, Yu.S. Prikhodko, Bulletin of South Ural State University. Construction and architecture, 16, No.2, 48-51 (2016)

23. T.G. Manukovskaya, Design of a system supplying heat power to industrial facilities taking account of heat-retaining capacities of buildings: thesis of cand.of techn.sc. Voronezh, (2012) [in Russian]

24. N.V. Kobyshev, Quality of heat supply of cities, 110127 (2004) 